Ігор Сергійович Романченко (доктор військових наук, професор) ${ }^{1}$

Михайло Михайлович Потьомкін (доктор технічних наук, с. н. с.) ${ }^{l}$

Олександр Станіславович Сирський ${ }^{2}$

${ }^{1}$ Центральний науково-дослідний інститут Збройних Сил Украӥни, Київ, Украӥна
${ }^{2}$ Генеральний штаб Збройних Сил Украӥни, Київ, Украӥна

\title{
МЕТОД ТРИКРИТЕРІАЛЬНОГО ЕВКЛІДОВОГО РАНЖУВАННЯ ТА ЙОГО ВИКОРИСТАННЯ ДЛЯ БАГАТОКРИТЕРІАЛЬНОГО ПОРІВНЯННЯ АЛЬТЕРНАТИВ
}

Наведено опис методу TOPSIS, призначеного для ранжування альтернатив, та результати його аналізу. Показано, що відомому методу TOPSIS притаманний недолік, пов'язаний із впливом ефекту компенсації на результати ранжування альтернатив. Зазначено, щуо в методах VIKOR ma MOORA для зменшення впливу иъього ефекту використовується додатковий показник. Відповідно комбінація методу TOPSIS ma підходу, використаного у методах VIKOR ma MOORA, дозволяє запропонувати новий метод - метод трикритеріального евклідового ранжування, який забезпечить підвищення обтрунтованості результатів за рахунок підвищення повноти порівняння альтернатив та зменшення впливу ефекту компенсації на них. Для иъього нового методу наведені формульні залежності, а також надано поетапний опис порядку проведення розрахунків. Можливість практичного застосування запропонованого методу продемонстрована на розрахунковому прикладі, для якого у літературних джерелах наводяться результати, отримані за відомими багатокритеріальними методами. Порівняння результатів розрахунків за відомими та новим методами свідчить, щзо використання запропонованого методу в комбінації з іншими методами дає можливість підвищити обтрунтованість розроблюваних рекомендації, а також визначити перспективні альтернативи, які залишились поза увагою інших методів. Ці результати дозволяють зробити висновок, щз використання розробленого методу трикритеріального евклідового ранжування може бути достатньо перспективним під час багатокритеріальної оптимізацї складних об'єктів.

Ключові слова: багатокритеріальне прийняття рішень; метод трикритеріального евклідового ранжування; метод TOPSIS; метод VIKOR; метод MOORA.

\section{Вступ}

Постановка проблеми. Нині під час дослідження проблемних питань як у галузі будівництва збройних сил, так і воєнного мистецтва широко використовуються багатокритеріальні методи, які грунтуються на порівнянні альтернатив $[1,2]$. При цьому використовувані методи повинні забезпечувати обгрунтованість отримуваних результатів.

Тому розроблення методів, які дозволяють підвищити обгрунтованість порівняння альтернатив, $\epsilon$, на наш погляд, актуальним напрямом досліджень.

Аналіз останніх досліджень і публікацій. Однією 3 достатньо поширених задач багатокритеріального порівняння альтернатив $€$ побудова їх пріоритетного ряду, для чого зазвичай розв'язується задача оптимізації у такій постановці.

Нехай $\epsilon$ множина альтернативних варіантів деякої системи, кожний 3 яких характеризується множиною показників. Значення показників задані матрицею $\left[\mathrm{E}_{\mathrm{ij}}\right](\mathrm{i}=1,2, \ldots, \mathrm{n} ; \mathrm{j}=1,2, \ldots, \mathrm{m}$, де $\mathrm{n}-$ кількість альтернатив; m - кількість показників). Окрім того, є множина коефіцієнтів важливості показників $\left(\mathrm{w}_{\mathrm{j}}, \mathrm{j}=1,2, \ldots, \mathrm{m}\right)$, а також для кожного 3 них визначений критерій оптимізації (на максимум або мінімум).

За такими даними необхідно побудувати пріоритетний ряд наявних альтернатив.

Відповідно до [3] одним 3 найбільш широко використовуваних для розв'язання цієї задачі $\epsilon$ метод TOPSIS, який орієнтований на оцінювання альтернатив відносно найкращої та найгіршої "еталонних" точок та передбачає виконання такої послідовності дій [4].

У першу чергу здійснюється нормалізація вихідних даних за формулою:

$$
\mathrm{e}_{\mathrm{ij}}=\mathrm{E}_{\mathrm{ij}} / \sqrt{\sum_{\mathrm{i}} \mathrm{E}_{\mathrm{ij}}^{2}}, \mathrm{i}=1, \ldots, \mathrm{n} ; \mathrm{j}=1, \ldots, \mathrm{m} .
$$


Для урахування важливості показників нормалізовані дані масштабують за формулою:

$$
v_{i j}=w_{j} e_{i j}, i=1, \ldots, n ; j=1, \ldots, m .
$$

Серед масштабованих даних для кожного ј-го показника визначають найкраще $\mathrm{V}_{\mathrm{j}}^{+}$та найгірше $\mathrm{V}_{\mathrm{j}}^{-}$значення як значення відповідних "еталонів".

Для кожної альтернативи евклідові відстані до найкращого та найгіршого "еталонів" розраховують за формулами:

$$
S_{i}^{+}=\sqrt{\sum_{j}\left(v_{i j}-V_{j}^{+}\right)^{2}}, S_{i}^{-}=\sqrt{\sum_{j}\left(v_{i j}-V_{j}^{-}\right)^{2}} .
$$

Узагальнений показник, який характеризує і-ту альтернативу, має вигляд

$$
\mathrm{C}_{\mathrm{i}}^{*}=\mathrm{S}_{\mathrm{i}}^{-} /\left(\mathrm{S}_{\mathrm{i}}^{+}+\mathrm{S}_{\mathrm{i}}^{-}\right)
$$

Найкращою вважається альтернатива, якій відповідає найбільше значення показника $C_{i}^{*}$.

Даючи загальну оцінку цьому методу, необхідно зазначити, що він забезпечує (наприклад, порівняно 3 відомим методом таксономії [2]) більшу повноту порівняння альтернатив унаслідок використання в ньому двох "еталонів".

Водночас методу TOPSIS, як i будь-якому іншому багатокритеріальному методу, заснованому на згортках, притаманна недосконалість, пов'язана 3 проявом ефекту компенсації [2, 5].

Для зменшення впливу зазначеного ефекту, наприклад, у методах VIKOR [6] та MOORA [7], до розгляду вводять додатковий показник.

У методі VIKOR для кожної альтернативи його значення розраховують за формулою:

$$
R_{i}=\max _{j}\left[\left|w_{j} \frac{\left(V_{j}^{+}-v_{i j}\right)}{V_{j}^{+}-V_{j}^{-}}\right|\right],
$$

а в методі MOORA -

$$
\mathrm{R}_{\mathrm{i}}=\max _{\mathrm{j}}\left[\left|\mathrm{V}_{\mathrm{j}}^{+}-\mathrm{v}_{\mathrm{ij}}\right|\right]
$$

Зрозуміло, що кращою альтернативою буде та, для якої значення $\mathrm{R}_{\mathrm{i}}$ буде найменшим.

Даючи загальну оцінку розглянутим методам (TOPSIS, VIKOR, MOORA), необхідно зазначити, що всі ці методи $\epsilon$ двокритеріальними, тобто фактично не різняться за повнотою порівняння альтернатив. Однак методи VIKOR та MOORA базуються на використанні адитивних згорток, у яких ефект компенсації має найбільший вплив на отримувані результати.
У методі TOPSIS (унаслідок використання в ньому евклідової міри для оцінювання відстаней альтернатив до еталонних точок) вплив цього ефекту дещо зменшується.

Загалом можна зробити висновок, що метод TOPSIS серед розглянутих є найбільш досконалим, однак і його результати не позбавлені впливу ефекту компенсації, що може мати наслідком похибки в ранжуванні альтернатив.

Подальшого зменшення прояву цього ефекту можна досягти шляхом поєднання ідей, покладених в основу розглянутих методів, тобто розробити новий метод - метод трикритеріального евклідового ранжування, який (окрім двох критеріїв методу TOPSIS) буде додатково враховувати і критерій, використаний у методах VIKOR та MOORA.

Мета статті - розробити новий метод - метод трикритеріального евклідового ранжування - та перевірити можливість його практичного використання на тестовому прикладі.

\section{Виклад основного матеріалу дослідження}

Узагальнюючи підходи до порівняння альтернатив, використані в розглянутих вище методах, можна зробити висновок, що найкраща альтернатива повинна відповідати трьом критеріям: бути найбільш віддаленою від найгіршої "еталонної" точки; бути максимально наближеною до найкращої "еталонної" точки; мати найменше відхилення від "еталонної" точки за показником, для якого така віддаленість є найбільшою.

Окрім того, для забезпечення можливості ранжування альтернатив за відповідністю цим критеріям розроблюваний метод має використовувати узагальнений показник, який дозволить побудувати пріоритетний ряд розглядуваних альтернатив залежно від їх віддаленості від "еталонних" точок.

Тоді новий метод трикритеріального евклідового ранжування буде складатися 3 такої послідовності етапів.

На першому етапі здійснюють підготовку вихідних даних, тобто складають матрицю $\left[\mathrm{E}_{\mathrm{ij}}\right]$, а також визначають значення коефіцієнтів важливості показників $\mathrm{w}_{\mathrm{j}}$ та критерії оптимізації показників (на максимум або мінімум).

На другому етапі здійснюють нормалізацію вихідних значень показників за формулами:

для показників, які потребують максимізації:

$$
e_{i j}=\frac{E_{i j}-\min _{i=1}^{n}\left(E_{i j}\right)}{\max _{i=1}^{n}\left(E_{i j}\right)-\min _{i=1}^{n}\left(E_{i j}\right)}, i=1, \ldots, n ;
$$

для показників, які потребують мінімізації: 


$$
e_{i j}=\frac{\max _{i=1}^{n}\left(E_{i j}\right)-E_{i j}}{\max _{i=1}^{n}\left(E_{i j}\right)-\min _{i=1}^{n}\left(E_{i j}\right)}, i=1, \ldots, n .
$$

При цьому використання формул (7) та (8) замість формули (1) пояснюється тим, що, на відміну від формули (1), вони забезпечують перебування нормалізованих значень усіх показників в однакових інтервалах.

На третьому етапі нормалізовані дані масштабують за формулою (2).

На четвертому етапі для кожного показника визначають найкращу $\mathrm{V}_{\mathrm{j}}^{+}$та найгіршу $\mathrm{V}_{\mathrm{j}}^{-}$ "еталонні" точки, на п’ятому етапі за формулами (3) для кожної альтернативи розраховують їх відстані до цих точок, а на шостому - 3 використанням формули (6) розраховують їх відстань від найкращої "еталонної" точки за показником, для якого ця відстань є найбільшою.

Вибір формули (6), а не (5) у даному разі пояснюється тим, що іiі результат є сумірним 3 відстанями, розрахованими за формулами (3).

На сьомому етапі для кожної альтернативи розраховують узагальнений показник, який характеризує ступінь іï відповідності обраним критеріям. Для цього використовують формулу:

$$
\mathrm{Q}_{\mathrm{i}}=\left(\mathrm{S}_{\mathrm{i}}^{+}+\mathrm{R}_{\mathrm{i}}\right) / \mathrm{S}_{\mathrm{i}}^{-}, \quad \mathrm{i}=1, \ldots, \mathrm{n} .
$$

Зрозуміло, що для альтернативи, яка повною мірою відповідає визначеним вище критеріям, значення $\mathrm{Q}_{i}$ буде найменшим. Тому на останньому, восьмому етапі альтернативи ранжують у пріоритетний ряд за збільшенням значення узагальненого показника $\mathrm{Q}_{\mathrm{i}}$. Тоді перша альтернатива цього впорядкованого ряду буде найкращою.

Додатково зазначимо, що за зовнішнім виглядом формула (9) $\epsilon$ подібною до формули, запропонованої у [8], для розрахунку узагальненого показника, за яким здійснюють ранжування альтернатив у методі трикритеріального ранжування. Однак, на відміну від розглядуваного методу, у [8] ранжування базується на використанні адитивних згорток, які, як було зазначено вище, характеризуються значним проявом ефекту компенсації. Тому схожість формули (9) та формули, запропонованої у [8], є лише зовнішньою внаслідок того, що в (9) використовуються евклідові відстані до "еталонів".

Для оцінювання можливості практичного використання розробленого методу розглянемо розрахунковий приклад 3 [2], який передбачає ранжування 10 альтернатив за шістьма показниками $\left(\mathrm{E}_{1}-\mathrm{E}_{6}\right)$ за однакової їх важливості. При цьому показники $\mathrm{E}_{1}-\mathrm{E}_{3}$ потребують максимізації, а решта
- мінімізації. Необхідно зазначити, що відповідно до [2] варіант № 3 є найкращим за методом таксономії, а варіант № 5 - за адитивною згорткою, тобто в разі використання однокритеріальних методів було отримано суперечливі результати ранжування альтернатив.

Вихідні дані для розрахунків наведено в табл. 1, a їх результати за запропонованим методом - у табл. 2.

Таблицяя 1

Значення показників, за якими оцінюються варіанти системи

\begin{tabular}{|c|c|c|c|c|c|c|}
\hline \multirow{2}{*}{$\begin{array}{c}\text { №, } \\
\mathrm{i}\end{array}$} & \multicolumn{7}{|c|}{ Вихідні значення показників } \\
\cline { 2 - 7 } & $\mathrm{E}_{\mathrm{i} 1}$ & $\mathrm{E}_{\mathrm{i} 2}$ & $\mathrm{E}_{\mathrm{i} 3}$ & $\mathrm{E}_{\mathrm{i} 4}$ & $\mathrm{E}_{\mathrm{i} 5}$ & $\mathrm{E}_{\mathrm{i} 6}$ \\
\hline 1 & 0,85 & 0,90 & 0,72 & 0,09 & 0,22 & 0,10 \\
\hline 2 & 0,74 & 0,94 & 0,83 & 0,06 & 0,18 & 0,25 \\
\hline 3 & 0,82 & 0,84 & 0,90 & 0,11 & 0,12 & 0,14 \\
\hline 4 & 0,78 & 0,81 & 0,69 & 0,13 & 0,26 & 0,16 \\
\hline 5 & 0,93 & 0,74 & 0,86 & 0,04 & 0,10 & 0,08 \\
\hline 6 & 0,74 & 0,87 & 0,83 & 0,09 & 0,14 & 0,23 \\
\hline 7 & 0,67 & 0,90 & 0,79 & 0,06 & 0,24 & 0,12 \\
\hline 8 & 0,85 & 0,84 & 1,00 & 0,13 & 0,28 & 0,14 \\
\hline 9 & 0,67 & 0,81 & 0,90 & 0,11 & 0,29 & 0,27 \\
\hline 10 & 0,78 & 0,90 & 0,97 & 0,18 & 0,06 & 0,18 \\
\hline
\end{tabular}

Аналіз результатів, наведених у табл. 2, свідчить, що найкращою є альтернатива № 3. При цьому ii перевага над альтернативою № 5 забезпечується меншими значеннями часткових показників $\mathrm{S}_{\mathrm{i}}^{+}$та $\mathrm{R}_{\mathrm{i}}$.

Тобто використання запропонованого методу не лише усунуло суперечливість, отриману внаслідок використання однокритеріальних методів, а й дало наочне обгрунтування для надання переваги альтернативі № 3 .

Таблиия 2

Результати розрахунків за запропонованим методом

\begin{tabular}{|c|c|c|c|c|c|}
\hline $\begin{array}{c}\text { №, } \\
i\end{array}$ & $\mathrm{~S}_{\mathrm{i}}^{-}$ & $\mathrm{S}_{\mathrm{i}}^{+}$ & $\mathrm{R}_{\mathrm{i}}$ & $\mathrm{Q}_{\mathrm{i}}$ & Ранг \\
\hline 1 & 0,2685 & 0,2009 & 0,1479 & 1,2993 & 3 \\
\hline 2 & 0,2500 & 0,2286 & 0,1476 & 1,5047 & 6 \\
\hline $\mathbf{3}$ & $\mathbf{0 , 2 5 3 3}$ & $\mathbf{0 , 1 6 1 3}$ & $\mathbf{0 , 0 8 2 9}$ & $\mathbf{0 , 9 6 4 0}$ & $\mathbf{1}$ \\
\hline 4 & 0,1461 & 0,2918 & 0,1667 & 3,1383 & 9 \\
\hline $\mathbf{5}$ & $\mathbf{0 , 3 3 3 5}$ & $\mathbf{0 , 1 8 4 4}$ & $\mathbf{0 , 1 6 6 7}$ & $\mathbf{1 , 0 5 2 6}$ & $\mathbf{2}$ \\
\hline 6 & 0,2168 & 0,2200 & 0,1295 & 1,6118 & 7 \\
\hline 7 & 0,2464 & 0,2418 & 0,1667 & 1,6578 & 8 \\
\hline 8 & 0,2555 & 0,2164 & 0,1532 & 1,4467 & 5 \\
\hline 9 & 0,1522 & 0,3240 & 0,1667 & 3,2244 & 10 \\
\hline 10 & 0,2821 & 0,2156 & 0,1667 & 1,3550 & 4 \\
\hline
\end{tabular}

\section{Висновки і перспективи подальших} досліджень

Таким чином, можна зробити висновок, що 
розроблений метод забезпечує можливість ранжування альтернатив на основі використання трьох критеріїв, що підвищує повноту порівняння альтернатив, та, відповідно, обгрунтованість отримуваних результатів. При цьому використання евклідової відстані до "еталонних" точок забезпечує зменшення впливу ефекту компенсації на результати порівняння альтернатив.

Можливість практичного використання $\begin{aligned} & \text { запропонованого методу } \\ & \text { розрахунковому прикладі. }\end{aligned}$
nоказана

Подальший розвиток проведених досліджень вбачається в програмній реалізації методу трикритеріального евклідового ранжування та перевірці ефективності його практичного використання на достатньому обсязі тестових даних.

\title{
Jimepamypa
}

1. Романченко I. С., Загорка О. М. Використання таксономічних методів при проведенні досліджень у воєнній справі // Зб. наук. пр. ЦНДІ ЗС України. Київ, 2007. № 3 (41). С. 5-16. 2. Загорка О. М., Мосов С. П., Сбитнєв А. І., Стужук П. І. Елементи дослідження складних систем військового призначення. Київ: НАОУ, 2005. 100 с. 3. Aruldoss M., Lakshmi T. M., Venkatesan V. P. A Survey on Multi Criteria Decision Making Methods and Its Applications // American Journal of Information Systems. 2013. Vol. 1. № 1. P. 31-43. 4. Ahmadi H., Rad M. S., Nilashi M., Ibrahim O., Almaee A. Ranking the micro level critical factors of electronic medical records adoption using TOPSIS method // Health Informatics - An International Journal. 2013, November.

Vol. 2. № 4. Р. 19-32. 5. Корнеенко В. П. Методы оптимизации. Москва: Высшая школа, 2007. 664 с. 6. Chang C.-L., Lin Y.-T. Using the VIKOR method to evaluate the design of a water quality monitoring network in a watershed // Int. J. Environ. Sci. Technol. 2014. № 11. P. 303310. 7. Brauers W. K. M., Zavadskas E. K. The MOORA method and its application to privatization in a transition economy // Control and Cybernetics. 2006. № 35 (2). P. 445469. 8. Свида І. Ю., Хомчак Р. Б., Потьомкін М. М. Метод трикритеріального ранжування та його використання для багатокритеріального порівняння альтернатив // Сучасні інформаційні технології у сфері безпеки та оборони. Київ, 2017. № 3 (30). C. 88-92.

\section{МЕТОД ТРЕХКРИТЕРИАЛЬНОГО ЕВКЛИДОВОГО РАНЖИРОВАНИЯ И ЕГО ИСПОЛЬЗОВАНИЕ ДЛЯ МНОГОКРИТЕРИАЛЬНОГО СРАВНЕНИЯ АЛЬТЕРНАТИВ}

\author{
Игорь Сергеевич Романченко (әоктор военных наук, профессор) ${ }^{1}$ \\ Михаил Михайлович Потемкин (доктор технических наук, с. н. с.) $)^{1}$ \\ Александр Станиславович Сырский ${ }^{2}$
}

\section{${ }^{1}$ Центральный научно-исследовательский институт Вооруженных Сил Украины, Киев, Украина ${ }^{2}$ Генеральный штаб Вооруженных Сил Украины, Киев, Украина}

Приведено описание метода TOPSIS, предназначенного для ранжирования альтернатив, $и$ результаты его анализа. Показано, что известному методу TOPSIS присущ недостаток, связанный с влиянием эффекта компенсации на результаты ранжирования альтернатив. Указано, что в методах VIKOR и MOORA для уменьшения влияния этого эффекта используется дополнительный показатель. Cоответственно комбинация метода TOPSIS и подхода, используемого в методах VIKOR и MOORA, позволяет предложить новый метод - метод трехкритериального евклидового ранжсирования, который обеспечит повышение обоснованности результатов за счет повышения полноты сравнения альтернатив и уменьшения влияния эффекта компенсаџии на них. Для этого нового метода приведены формульные зависимости, а также дано поэтапное описание порядка проведения расчетов. Возможность практического использования предложенного метода показана на расчетном примере, для которого в литературных источниках приводятся результаты, полученные $c$ использованием известных многокритериальных методов. Сравнение результатов расчетов, полученных с использованием известных и нового методов, свидетельствует о том, что использование предложенного метода в комбинации с другими методами дает возможность повысить обоснованность разрабатываемых рекомендаиий, а также найти перспективные альтернативы, которые не были выявлены другими методами. Эти результаты позволяют сделать вывод, что применение разработанного метода трехкритериального евклидового ранжирования может быть достаточно перспективным для многокритериальной оптимизации сложных объектов.

Ключевые слова: многокритериальное принятие решений; метод трехкритериального евклидового ранжсирования; метод TOPSIS; метод VIKOR; метод MOORA.

\section{THE THREE CRITERIAL EUCLIDEAN RANKING METHOD AND ITS USE FOR A MULTICRITERIAL COMPARISON OF ALTERNATIVES}




\section{Ighor Romanchenko (Doctor of military sciences, professor) ${ }^{1}$ \\ Mykhajlo Potomkin (Doctor of technical sciences, senior research fellow) ${ }^{2}$ Oleksandr Syrskyi ${ }^{2}$

\author{
${ }^{1}$ Central research institute of Ukrainian armed forces, Kyiv, Ukraine \\ ${ }^{2}$ General staff of Ukrainian armed forces, Kyiv, Ukraine
}

There is description of the TOPSIS method for ranking alternatives and the results of its analysis. It is shown that the well-known TOPSIS method has a drawback associated with the influence of the compensation effect on the ranking results of alternatives. It is indicated that in the VIKOR and MOORA methods an additional indicator is used to reduce the influence of this effect. Accordingly, the combination of the TOPSIS method and the approach used in the VIKOR and MOORA methods allows us to propose a new method - the three-criteria Euclidean ranking method, which will increase the validity of the results by increasing the completeness of the comparison of alternatives and reducing the effects of the compensation effect on them. For this new method, there are given formulaic dependencies, and it is also given a step-by-step description of the procedure for performing calculations. The possibility of practical use of the proposed method is shown in computational exampl for which the obtained results using the well-known multi-criteria methods are given in the literature. Comparison of the calculations results obtained by using known and new methods suggests that using the proposed method in combination with other methods can increase the validity of the recommendations or find perspective alternatives that have not been identified by other methods. These results allow us to conclude that the application of the developed three-criteria Euclidean ranking method can be quite perspective for multi-criteria optimization of complex objects.

Keywords: multi-criteria decision making; the three-criteria Euclidean ranking method; TOPSIS method; VIKOR method; MOORA method.

\section{References}

1. Romanchenko I.S., Zagorka O.M. (2007). Using taxonomy methods for military research [Vykorystannja taksonomichnykh metodiv pry provedenni doslidzhenj $u$ vojennij spravi], Col. of scient. pap. CRI of AF of Ukraine, № 3 (41), pp. 5-16. 2. Zagorka O.M., Mosov S.P., Sbitniev A.I., Stuzhuk P. I. (2005). Complex military systems research's componentry [Elementy doslidzhennja skladnykh system vijsjkovogho pryznachennja], NADU, Kyiv, 100 p. 3. Aruldoss M., Lakshmi T. M., Venkatesan V. P. (2013). A Survey on Multi Criteria Decision Making Methods and Its Applications, American Journal of Information Systems. Vol. 1. № 1. pp. 31-43. 4. Ahmadi H., Rad M. S., Nilashi M., Ibrahim O., Almaee A. (November, 2013). Ranking the micro level critical factors of electronic medical records adoption using TOPSIS method. Health Informatics - An International
Journal. Vol. 2. № 4. pp. 19-32. 5. Korneenko, V.P. (2007). Metodyi optimizatsii [Methods for optimization], High school, Moscow, 664 p. 6. Chang C.-L., Lin Y.-T. (2014). Using the VIKOR method to evaluate the design of a water quality monitoring network in a watershed. Int. J. Environ. Sci. Technol. № 11 . pp. 303-310. 7. Brauers W. K. M., Zavadskas E. K. (2006). The MOORA method and its application to privatization in a transition economy, Control and Cybernetics. № 35 (2). pp. 445-469. 8. Svuda I.U., Potjomkin M. M., Khomchak R. B. (2017). Method of threecriterial ranking and its use for a multi-criterial comparison of alternatives [Metod trykryterialjnogho ranzhuvannja ta jogho vykorystannja dlja baghatokryterialjnogho porivnjannja aljternatyv], Modern Information Technologies in the Sphere of Security and Defence, № 3 (30), pp. 88-92. 